\title{
Ketogenic Diet with Severe Altered States of Consciousness in Children
}

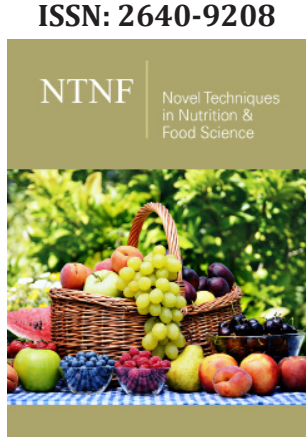

*Corresponding author: Gregory Hansen, Division of Pediatric Critical Care, Jim Pattison Children's Hospital, Canada

Submission: 酱 May 18, 2021

Published: 战 May 27, 2021

Volume 6 - Issue 1

How to cite this article: Casey Napper, Carolyn Olver, Katia Hucl, Katelynn Foth, Gregory Hansen. Ketogenic Diet with Severe Altered States of Consciousness in Children. Nov Tech Nutri Food Sci. 6(1). NTNF. 000628. 2021. DOI: 10.31031/NTNF.2021.06.000628

Copyright@ Gregory Hansen. This article is distributed under the terms of the Creative Commons Attribution 4.0 International License, which permits unrestricted use and redistribution provided that the original author and source are credited.

\author{
Casey Napper ${ }^{1}$, Carolyn Olver ${ }^{1}$, Katia Hucl ${ }^{1}$, Katelynn Foth $^{1}$ and Gregory \\ Hansen ${ }^{2 *}$ \\ ${ }^{1}$ Saskatchewan Health Authority, Jim Pattison Children's Hospital, Canada \\ ${ }^{2}$ Division of Pediatric Critical Care, Jim Pattison Children’s Hospital, Canada
}

\begin{abstract}
Introduction: Recommendations for children with severe altered states of consciousness does not include ketogenic nutrition. The purpose of this study was to evaluate short-term quality control outcomes for a ketogenic diet in this population, document challenges, and guide next steps.

Methods: We performed a 19-month descriptive cohort study that included children, <17 years of age, admitted to the pediatric intensive care unit. Short-term quality control outcomes included increase in beta-hydroxybutyrate, number of episodes of blood glucose levels below $4 \mathrm{mmol} / \mathrm{L}$, development of acidosis ( $\mathrm{pH}<7.3$ ), and clinical development of kidney stones.
\end{abstract}

Results: Thirteen patients with stroke, traumatic brain injury or hypoxic ischemic encephalopathy were evaluated. The average beta-hydroxybutyrate level was $1.7 \mathrm{mmol} / \mathrm{L}$, one patient (8\%) developed hypoglycemia, seven patients (54\%) developed acidosis, and no kidney stones were documented. Initiation of enteral nutrition was delayed, and the average protein intake was $0.58 \mathrm{~g} / \mathrm{kg}$.

Conclusion: Modifications to our ketogenic protocol included changes to the ketogenic ratio, and earlier wean to optimize protein, and the goal of positive ketones from both serum and urine testing only.

Keywords: Acute brain injuries; Children; Enteral formulas; Ketogenic diet; Intensive care

Abbreviations: ASC: Altered States of Consciousness; BHB: Beta-Hydroxy Butyrate; GCS: Glasgow Coma Scale; HIE: Hypoxic Ischemic Encephalopathy; PICU: Pediatric Intensive Care Unit; REE: Resting Energy Expenditure; TBI: Traumatic Brain Injury

\section{Introduction}

Severe brain injury is the leading cause of mortality and morbidity in children injured over one year of age [1]. In the Pediatric Intensive Care Unit (PICU), severe Altered States of Consciousness (ASC) are typically seen after Traumatic Brain Injury (TBI), stroke, or Hypoxic Ischemic Encephalopathy (HIE) secondary to drowning, cardiac arrest, or asphyxiation. To improve outcomes for these patients, optimizing nutritional support continues to gain momentum. Ketogenic diets as a therapeutic in severe ASC is a burgeoning field. In brain injury animal models, ketones have demonstrated significant neuroprotective effects through improved mitochondrial metabolic efficiency, decreased oxidative stress, preventing metabolic deficits, attenuating apoptosis, and reducing excitotoxicity [2-10]. In humans, their use has been suggested or trialed in a number of chronic neurologic conditions including Alzheimer's disease, severe refractory epilepsy, intracranial neoplasms, Parkinson's [11], and mitochondrial diseases [12]. Human data on severe ASC and ketones is limited. In adults, Robertson et al. [13] studied the effect of glucose administration after head injury and reported how it was the major cause of suppressed ketogenesis and may increase lactic acidosis. Ritter et al. [14] concluded that a carbohydrate-free-diet not only maintained stable blood sugars but reduced cerebral edema. In critically ill pediatric patients with refractory status epilepticus. A therapeutic ketogenic diet was safe and led to improved seizure outcomes [15]. At present, recommendations for nutritional support in children with severe ACS does not include a ketogenic diet. Therefore, the purpose of this study was to evaluate short-term quality control outcomes for a ketogenic diet in severe pediatric ACS, document challenges, and guide next steps. 


\section{Research Design and Methodology}

\section{PICU ketogenic diet development}

At our hospital there is a well-established ketogenic diet program for children with epilepsy. Significant consultation with this service was done prior to the development of our pilot ketogenic protocol and throughout the study period. Balancing ketosis and protein provision became the two major discussion points. Ketosis via starvation was not consistent with the benefits of early enteral nutrition in critical illness, and consequently was not considered. Additionally, although $1.5-3 \mathrm{~g} / \mathrm{kg}$ protein is suggested in TBI [16] to prevent loss of lean body mass, support growth, and avoid negative nitrogen balance [17], protein optimization below $1.5 \mathrm{~g} / \mathrm{kg}$ was expected to achieve ketosis.

\section{Initial ketogenic protocol}

Ketogenic and PICU dietitians were involved in the care of each patient upon initiation and throughout the patient's PICU stay. Nutrition assessment occurred upon admission to the PICU, and upon confirmation of the ketogenic diet initiation. Ketogenic therapy duration was fourteen days of enteral feeds. Thereafter, patients were transitioned over two to three days to either a typical enteral feeding formula or a typical oral diet that was age appropriate. The ketogenic diet plan included initiation of enteral feeds with a ready-to feed ketogenic tube feed formula (KetoVie 4:1 Vanilla, Cambrooke Therapeutics) within 24-48h of admission. The formula was hypercaloric $(1.4 \mathrm{kcal} / \mathrm{ml})$, which was diluted half and half with water $(0.7 \mathrm{kcal} / \mathrm{ml})$, thereby providing a more isocaloric concentration and mitigating possible gastrointestinal intolerance. The ready-to-feed formula provided a 4:1 ketogenic ratio (i.e. 4 grams fat: 1 gram combined carbohydrate + protein), a lower net carbohydrate per milliliter allowed for a higher protein concentration than comparable ketogenic formulas, and contained added medium chain triglycerides and carnitine which assisted in achieving ketosis. As admission weight increased, protein provision was less optimal, and volume of protein supplementation via a liquid hydrolyzed protein fortifier (LiquiProtein, Abbott) was increased. The amount of added protein was weight-determined and ordered in a standard amount added to the ketogenic formula:water mixture. The addition of protein fortifier to the $4: 1$ ratio diluted formula decreased the ketogenic ratio to $3.4: 1$ in the lowest weight group, and progressively lower in each subsequent weight group, with the heaviest patients receiving the lowest ketogenic ratio of $2: 1$, in order to optimize protein intake.

Our goals were to meet but not exceed energy requirements, and to titrate caloric provision based on measured Resting Energy Expenditure (REE). In absence of indirect calorimetry in our PICU, we used a ventilator-derived calculation as a surrogate for measured REE [18]. This surrogate measure is more accurate in patients $>15 \mathrm{~kg}$. Study Design and Patient Selection We performed a 19-month prospective descriptive cohort study including children $<17$ years of age to the PICU with severe ASC. Inclusion criteria reflected i) patients with a Glasgow Coma Scale (GCS) $\leq 8$ secondary to TBI; or ii) patients with a GCS $\leq 8$, hyperlactemia and absent electroencephalographic (EEG) reactivity secondary to a stroke; or iii) patients with a GCS $\leq 8$, hyperlactemia and absent EEG reactivity secondary to HIE; and iv) greater than $15 \mathrm{~kg}$ in weight for accurate ventilatory estimates on REE to be made. The exclusion criterion removed all patients with metabolic conditions that a ketogenic diet would exacerbate including pyruvate carboxylase deficiency, porphyria or fat metabolism disorders [carnitine deficiency (primary), carnitine palmitoyltransferase deficiency, carnitine translocase deficiency, b-oxidation defects, medium-chain acyl dehydrogenase deficiency, long-chain acyl dehydrogenase deficiency, short-chain acyl dehydrogenase deficiency, longchain 3-hydroxyacyl-CoA deficiency, and medium-chain 3-hydroxyacylCoA deficiency]. Ethical approval was provided by The University of Saskatchewan Research Ethics Board (U of S Bio \#763).

\section{Monitoring}

Blood glucose was monitored every 4 hours until stable, with a hypoglycemia protocol in place for measurements $<2.5 \mathrm{mmol} / \mathrm{L}$. Serum Beta Hydroxy Butyrate (BHB) was measured daily and urine ketones twice daily to evaluate ketosis. Blood gases were monitored daily to evaluate incidence of metabolic acidosis. Quality control outcomes and variables collected the following short-term quality control outcomes were evaluated over a two-week period: i) increase in BHB; ii) number of episodes of blood glucose levels below $4 \mathrm{mmol} / \mathrm{L}$; iii) development of acidosis ( $\mathrm{pH}<7.3$ ); and iv) clinical development of kidney stones. The following variables were collected during the two-week period: age, sex, primary neurologic injury, daily estimated and measured REE, weight at admission and per PICU protocol when stable, daily arterial blood gases, blood glucose, record of sedation and neuromuscular blockade, neuroimaging, urinalysis, and EEG interpretations.

\section{Statistical methods}

Descriptive statistics were utilized, including mean and standard deviation, median or proportions where appropriate.

\section{Result}

Table 1: Patient demographics and clinical characteristics $(n=13)$.

\begin{tabular}{|c|c|}
\hline Age, year $^{\mathrm{a}}$ & $11.8(4.0)$ \\
\hline${\text { Weight, } \mathrm{kg}^{\mathrm{a}}}$ & $53.7(16.0)$ \\
\hline Male sex, n(\%) & $9(69.2)$ \\
\hline Admitting diagnosis, n(\%) & $3(23.1)$ \\
Stroke & $7(53.8)$ \\
TBI & $3(23.1)$ \\
\hline
\end{tabular}

HIE: Hypoxic Ischemic Encephalopathy; TBI: Traumatic Brain Injury. amean (standard deviation). 
Thirteen patients with stroke, traumatic brain injury or hypoxic ischemic encephalopathy are summarized in Table 1. Individualized and cohort data on nutrition and quality control outcomes are summarized in Table 2. The average beta-hydroxybutyrate level was $1.7 \mathrm{mmol} / \mathrm{L}$, one patient (8\%) developed hypoglycemia, seven patients (54\%) developed acidosis, and no kidney stones were documented. Initiation of enteral nutrition was delayed, and average protein intake was $0.58 \mathrm{cg} / \mathrm{kg}$.

Table 2: Nutrition and biochemical outcomes $(n=13)$.

\begin{tabular}{|c|c|c|c|c|c|c|c|c|c|c|}
\hline $\begin{array}{l}\text { Patient } \\
\text { Number }\end{array}$ & $\begin{array}{c}\text { Enteral Nutritio } \\
\mathbf{n} \\
\text { Initiatio } \\
\mathbf{n}(\mathrm{hrs})\end{array}$ & $\begin{array}{c}\text { Length on } \\
\text { Ketogenic } \\
\text { Diet (days) }\end{array}$ & $\begin{array}{l}\text { Measured REE } \\
\text { vs. WHO REE }\end{array}$ & $\begin{array}{c}\text { Kcal/kg } \\
\text { Receiveda }\end{array}$ & $\begin{array}{l}\text { Protein } \\
\text { (g/kg) }\end{array}$ & $\begin{array}{c}\text { Hypoglycemia } \\
\text { ( }<4 \mathrm{mmol} / \mathrm{L})\end{array}$ & $\begin{array}{c}\text { Acidosis } \\
\text { (pH ds< } \\
7.3 \text { ) }\end{array}$ & $\begin{array}{l}\text { Renal } \\
\text { Stones }\end{array}$ & $\begin{array}{c}\text { BHB } \\
\text { Levela } \\
(\mathrm{mmol} / \mathrm{L} \\
)\end{array}$ & $\begin{array}{c}\text { Urine } \\
\text { Ke- } \\
\text { tones }^{\mathrm{b}, \mathrm{c}}\end{array}$ \\
\hline 1 & $>72$ & 12 & $28: 58$ & 34.5 & 0.98 & No & No & No & 2.9 & 2.5 \\
\hline 2 & $>72$ & 14 & $19: 32$ & 15.4 & 0.56 & No & No & No & 2.7 & 2 \\
\hline 3 & $36-48$ & 10 & $20: 23$ & 17 & 0.66 & No & Yes & No & 2.8 & 2 \\
\hline 4 & $12-24$ & 14 & $23: 25$ & 21.4 & 0.54 & No & Yes & No & 1.3 & 2 \\
\hline 5 & $24-36$ & 4 & $23: 30$ & 9.3 & 0.36 & No & No & No & 2.4 & 2 \\
\hline 6 & $24-36$ & 15 & $21: 19$ & 22.5 & 0.63 & No & No & No & 1.5 & 2 \\
\hline 7 & $48-56$ & 5 & 19:15 & $\mathrm{N} / \mathrm{A}$ & $\mathrm{N} / \mathrm{A}$ & No & No & No & 1.3 & 2 \\
\hline 8 & $>72$ & 17 & $14: 21$ & 8.5 & 0.24 & No & Yes & No & 0.4 & 1 \\
\hline 9 & $>72$ & 16 & 19:18 & 11.4 & 0.39 & No & Yes & No & 1.3 & 2 \\
\hline 10 & $36-48$ & 13 & $17: 17$ & 16.4 & 0.45 & Yes & No & No & 1.6 & 1 \\
\hline 11 & $48-56$ & 15 & $30: 24$ & 25.6 & 0.77 & No & Yes & No & 0.9 & 2 \\
\hline 12 & $56-72$ & 21 & $31: 27$ & 27.7 & 1.01 & No & Yes & No & 2.2 & 2 \\
\hline 13 & $36-48$ & 5 & $17: 18$ & 13.8 & 0.33 & No & Yes & No & 0.3 & 0 \\
\hline \multirow{2}{*}{ Cohort } & \multirow{2}{*}{$48-56^{c}$} & \multirow{2}{*}{$12.4(4.9)^{\mathrm{a}}$} & \multirow{2}{*}{$22: 25$} & \multirow{2}{*}{$18.6(7.6)^{\mathrm{a}}$} & \multirow{2}{*}{$\begin{array}{c}0.58 \\
(0.2)^{\mathrm{a}}\end{array}$} & \multirow{2}{*}{$8 \%$} & \multirow{2}{*}{$54 \%$} & \multirow{2}{*}{$0 \%$} & 1.7 & \multirow{2}{*}{$2^{c}$} \\
\hline & & & & & & & & & $(0.8)^{\mathrm{a}}$ & \\
\hline
\end{tabular}

REE: Resting Energy Expenditure; BHB: serum Beta Hydroxybutyrate. amean (standard deviation); btarget urine ketones $2+$ to $3+(8-16 \mathrm{mmol} / \mathrm{L})$; cmedian.

\section{Discussion}

Managing thirteen pediatric patients with severe ACS and ketogenic nutrition presented numerous challenges. However, these challenges allowed for informed revisions and the creation of our current protocol (Supplement 1) that may be considered by other tertiary centers. Our ketogenic protocol aimed for two seemingly opposing nutrition goals: adequate protein provision for critical illness and ketosis for the goal of neuroprotection. Although we recognized that a high protein ketogenic diet would be problematic with the conversion of glucogenic amino acids into glucose through gluconeogenesis, our mean protein provision remained poor at $0.58 \mathrm{~g} / \mathrm{kg} /$ day. Adding LiquiProtein at the onset of enteral feeds was also not optimal, as this reduced the ketogenic ratio and mitigated ketosis. When utilizing ketogenic diets for seizure control, typical targets are urine ketones of $2+$ to $3+(8-16 \mathrm{mmol} / \mathrm{L})$ on Chemstrip 7, BHB between 3-6mmol/L, and/or the reduction of seizures. In our initial protocol, biochemical targets were used to determine if optimal ketosis was achieved. Since the efficacy of ketosis could not be observed through the absence of seizures, it was unclear when our patient was "ketotic enough" to achieve neuroprotection. Currently there is no human data on what level of measurable ketones provide neuroprotection in severe ACS and/ or if the effect is titratable. Since a healthy individual consuming a typical diet would not have urine or blood ketones present, are the presence of any ketones indicating a benefit? Initiating and advancing early enteral nutrition is a well-documented struggle in the PICU. Multiple factors contributed to our delay in adequate enteral nutrition including surgical intervention and/or other procedures, high dose vasoactive medications affecting splanchnic perfusion, medical imaging, and intubation/extubation attempts. Each of these scenarios often requires lengthy fasting periods which make it difficult to initiate and advance enteral nutrition to goal volumes and often contribute to the development of iatrogenic malnutrition [19].

Our initial goal was to meet the calculated REE with diluted formula to avoid potential overfeeding and possible gastrointestinal intolerance associated with hypercaloric feeds. We also assumed that enteral nutrition would be running at approximately $100 \%$ of the Holiday-Segar total fluid intake. However, in practice, the volume available for nutrition due to numerous intravenous infusions resulted in underfeeding with diluted formula. Consequently, the formula required several adjustments of calorie and protein ratios and created an opportunity for increased confusion when being prepared by nursing staff. The intention of having nursing staff prepare formula was to facilitate initiation of the protocol after regular hours or in absence of a dietitian. In reality, the ketogenic protocol was not started until after a discussion with a dietitian during interdisciplinary rounds. Our initial protocol also aimed to provide a ketogenic diet enterally for two weeks. It was assumed that the patients would be unable to eat orally for at least two 
weeks due to their severe brain injury. Some patients, however, were extubated earlier, with the decision to allow for a progression to a standard oral diet. The goal duration for the patient to remain on the ketogenic diet was then shortened to seven to fourteen days and clarification was made to ensure no oral ketogenic diets would be utilized.

It is worth mentioning that during the time of study, our facility did not have access to indirect calorimetry. We used a surrogate calculation utilizing carbon dioxide output from our ventilator to glean measured REE and aimed to personalize our energy goals towards it. Calculated REE tends to overestimate measured REE [20], and children with traumatic brain injury are often hypometabolic secondary to the various therapeutic treatments such as hypothermic cooling, and neuromuscular blockade [21]. Our data was consistent with these observations and suggested wide discrepancies between calculated and measured REE.

\section{Conclusion}

Based on the challenges noted, our current protocol (Supplement 1) reflects targeted ketosis for neuroprotection in the first ten days post brain injury, with the understanding that protein provision will remain suboptimal for the duration of the ketogenic diet. To improve ketosis, patients are started on a 4:1 ketogenic ratio. We chose to change our formula mixture to 70:30 KetoVie 4:1 Vanilla: water to provide $1 \mathrm{kcal} / \mathrm{ml}$, given there is often less volume available for enteral nutrition. If a more complex ketogenic formula with modular products is required, it will be prepared by food services to prevent potential errors. Second, to optimize protein as soon as possible, we now start weaning off the ketogenic diet on day 10 (rather than day 14) and continue weaning over 2-4 days by adding additional protein until goal protein for TBI management $(1.5-3 \mathrm{~g} / \mathrm{kg} /$ day) is achieved. After this, carbohydrates are added and a standard enteral formula for age is transitioned. Finally, the goal ranges for urine and serum ketones $(2-3+$ and $3-6 \mathrm{mmol} / \mathrm{L}$ respectively) have been removed from the order set; instead, the presence of ketones from both serum and urine testing will be considered a successful level of ketosis for this patient population.

\section{Supplement}

\section{Ketogenic Diet Initiation for Severe Brain Injury Traumatic or Hypoxic Brain Injury with GCS $\leq 8$ and $\geq 15 \mathrm{~kg}$}

KETO-TBI PROTOCOL INITIATION ORDERS: (Please transcribe the following into Physicians Orders):

1. No dextrose-containing IV fluids

2. No carbohydrate-containing medications (see reverse for reference); Consult Pharmacy re: alternatives to CHOcontaining meds.

3. Blood glucose monitoring $\mathrm{q} 4 \mathrm{~h}$ until stable on goal feeds

1. If GST $<2.5 \mathrm{mmol} / \mathrm{L}$, notify physician to correct with appropriate per kg dextrose load. Recheck GST in 10min and consider more frequent glucose monitoring thereafter.

4. Bedside urine ketones BID (using Chem-strip 7 strips) (GOAL: Presence of ketones).

5. Blood gas and Serum Ketones ("Beta Ketone") q24h (GOAL: Presence of ketones). (Beta Ketone requires $0.5 \mathrm{ml}$ blood drawn in a dark green tube)

6. If MRI performed, please inform Dr. Greg Hansen, and ask for "MRS for ketone bodies" with the MRI request.

7. Enteral feeds initiated within 24-48h of admission; consult PICU RD and Ketogenic Diet RD.

8. Feeds initiated as follows based on patient weight. (KetoVie Liquid formula to be ordered from Food \& Nutrition) (Figure $1)$.



Figure 1. 
a) Ongoing Management: PICU RD and Ketogenic Diet RD will adjust recipe as needed to optimize calories, protein, and ketogenic ratio based on serum and urine ketone levels.

b) Length of Therapy: Diet to continue via tube-feed for MINIMUM 1-week post-injury, up to 2 weeks if possible. At the tenday mark RD will start adding extra protein, which will decrease the ketogenic ratio, and may reduce ketosis. Diet will be transitioned to a standard formula at 14 days. NO ORAL KETO DIETS will be started, if the patient is eating orally prior to 14 days discontinue the Keto Diet and Protocol (feed standard diet).

1) Diet Order Entry via SCM: RN to order KetoVie Liquid required in a $24 \mathrm{~h}$ period through SCM. Please add approximately $20 \%$ extra to account for priming/spillage.

2) NOTE: Ketovie is only making up $70 \%$ of the total volume.

3) New Order Entry $\rightarrow$ Diet \& Supplements $\rightarrow$ Tube Feeding Pediatric $\rightarrow$ Tube Feed Product: KetoVie Liquid Volume:_ml for 24 hours.

4) Keto Bloodwork Order Entry via SCM: Search laboratory orders for "Beta Ketone".

\section{Medication pearls for Ketogenic Diet:}

1. Most suspensions will contain sugar.

2. Most IV formulations are keto friendly, as long as they are not mixed with dextrose.

3. At the start of the admission orders, please indicate to pharmacy that patient is on a ketogenic diet and to review medications.

4. Most tablets have low amounts of carbohydrate making them a great alternative. If they are water soluble, we can dissolve and dose tablets (eg. Dissolve $100 \mathrm{mcg}$ tablet in $10 \mathrm{~mL}$ to get $10 \mathrm{mcg} / \mathrm{mL}$ solution, or we can round to nearest $1 / 4$ or $1 / 2$ tablet size and crush and administer).

\section{Commonly ordered medications in PICU for traumatic brain injury}

Table 3.

\begin{tabular}{|c|c|c|c|}
\hline Drug & Keto-friendly & Indication & Alternative \\
\hline Glycerin & NO & Medication Suspension & Discuss alternatives with pharmacy and RD \\
\hline Nystatin & NO & Mouth care & \\
\hline Sucralfate & NO & Stress ulcer prophylaxis & $\begin{array}{l}\text { PPI suspension or tablet (eg: lansoprazole) } \\
\text { *note: PPI suspension does not contain sugar* } \\
\text { Tablet sizes: } 15 \mathrm{mg} / 30 \mathrm{mg} \text { (can be split) }\end{array}$ \\
\hline Acetaminophen & $\begin{array}{l}\text { SYRUP: NO } \\
\text { Tablets: YES }\end{array}$ & Pain/fever & $\begin{array}{l}\text { Use } 325 \mathrm{mg} \text { tablets, round to the nearest } 1 / 4 \text { or } \\
\qquad 1 / 2 \text { tablet }\end{array}$ \\
\hline Ibuprofen & $\begin{array}{l}\text { SYRUP: NO } \\
\text { Tablets: YES }\end{array}$ & Pain/fever & $\begin{array}{l}\text { Use } 200 \mathrm{mg} \text { tablet and round to the nearest } 1 / 4 \\
\text { or } 1 / 2 \text { tablet }\end{array}$ \\
\hline Fentanyl & IV: YES & Sedation/Pain & \\
\hline Morphine & $\begin{array}{l}\text { IV: YES } \\
\text { SYRUP: NO } \\
\text { TABLETS: YES }\end{array}$ & Sedation/Pain & $\begin{array}{l}\text { For oral dosing, use tablets: available as } 5 \mathrm{mg} \\
\text { and } 10 \mathrm{mg} \text { tablets }\end{array}$ \\
\hline Midazolam & IV: YES & Sedation/seizures & \\
\hline Lorazepam & $\begin{array}{l}\text { IV: YES } \\
\text { Suspension: NO } \\
\text { Tablets: Yes }\end{array}$ & Seizures/sedation & $\begin{array}{c}\text { Available as } 0.5 \mathrm{mg}, 1 \mathrm{mg} \text {, and } 2 \mathrm{mg} \text { tablets. Can } \\
\text { dissolve and dose or round to nearest } 1 / 4 \text { or } 1 / 2 \\
\text { tablet }\end{array}$ \\
\hline $\begin{array}{l}\text { Dexmedetomidine } \\
\text { (Precedex) }\end{array}$ & IV: YES & Sedation & \\
\hline $\begin{array}{l}\text { Chloral Hydrate } \\
\text { suspension }\end{array}$ & Liquid: NO & Sedation & Optimize other sedatives \\
\hline Clonidine & $\begin{array}{l}\text { Liquid: NO } \\
\text { Tablets: YES }\end{array}$ & $\begin{array}{l}\text { Adjunct analgesia/ } \\
\text { Sedation/ Blood pressure }\end{array}$ & $\begin{array}{l}\text { Tablets are available as } 25 \mathrm{mcg}, 100 \mathrm{mcg} \text {, and } \\
200 \mathrm{mcg} \text { tablets. Please round to the nearest } 1 / 4 \text {, } \\
1 / 2 \text { or whole tablet. Can also dissolve and dose } \\
\text { tablets if required. }\end{array}$ \\
\hline Phenytoin & $\begin{array}{l}\text { IV: YES } \\
\text { Suspension: NO } \\
\text { Tablets: YES }\end{array}$ & Seizures & $\begin{array}{l}\text { Available as } 50 \mathrm{mg} \text { immediate release tabletsround } \\
\text { to the nearest } 1 / 4,1 / 2 \text {, or full tablet. }\end{array}$ \\
\hline Levetiracetam (Keppra) & $\begin{array}{l}\text { Suspension: YES- } \\
\text { (suspension is ketof- } \\
\text { riendly) }\end{array}$ & Seizures & \\
\hline Potassium chloride & $\begin{array}{l}\text { Elixir - NO } \\
\text { IV- YES }\end{array}$ & Potassium replacement & $\begin{array}{l}\text { Potassium citrate effervescent (K-lyte) } 25 \mathrm{mEq} \\
\text { tablet can be dissolved and dosed as needed }\end{array}$ \\
\hline
\end{tabular}




\begin{tabular}{|c|c|c|c|}
\hline $\begin{array}{c}\text { Heparin } \\
\text { (25000 unit/500ml bag) }\end{array}$ & $\begin{array}{c}\text { NO } \\
\text { (Commercial bag comes } \\
\text { in } \\
5 \% \text { dextrose) }\end{array}$ & Anticoagulation & $\begin{array}{l}\text { Consult pharmacy for mixing instructions in } \\
\text { Normal Saline }\end{array}$ \\
\hline Cefazolin & IV: YES & \multirow{6}{*}{ Infections } & \\
\hline Ceftriaxone & IV: YES & & \\
\hline Cefotaxime & IV: YES & & \\
\hline Vancomycin & IV: YES & & \\
\hline Tazocin & IV: YES & & \\
\hline Clindamycin & IV - NO (mixed in D5W) & & \\
\hline
\end{tabular}

HIE: Hypoxic Ischemic Encephalopathy; TBI: Traumatic Brain Injury. amean (standard deviation).

\section{References}

1. Langlois JA (2001) Traumatic brain injury in the united states: Assessing outcomes in children. Center for Disease Control and Prevention.

2. Appelberg KS, Hovda DA, Prins ML (2009) The effects of a ketogenic diet on behavioral outcome after controlled cortical impact injury in the juvenile and adult rat. J Neurotrauma 26(4): 497-506.

3. Davis LM, Pauly JR, Readnower RD, Rho JM, Sullivan PG (2008) Fasting is neuroprotective following traumatic brain injury. J Neurosci Res 86(8): 1812-1822.

4. Bryant YD, Prins ML, Hovda DA, Harris NG (2011) Ketogenic diet prevents alterations in brain metabolism in young but not adult rats after traumatic brain injury. J Neurotrauma 28(9): 1813-1825.

5. Greco T, Glenn TC, Hovda DA, Prins ML (2016) Ketogenic diet decreases oxidative stress and improves mitochondrial respiratory complex activity. J Cereb Blood Flow Metab 36(9): 1603-1613.

6. Prins ML, Fujima LS, Hovda DA (2005) Age-dependent reduction of cortical contusion volume by ketones after traumatic brain injury. J Neurosci Res 82(3): 413-420.

7. Prins ML, Hovda DA (2009) The effects of age and ketogenic diet on local cerebral metabolic rates of glucose after controlled cortical impact injury in rats. J Neurotrauma 26(7): 1083-1093.

8. Schwartzkroin PA, Wenzel HJ, Lyeth BG, Poon CC, Delance A, et al. (2010) Does ketogenic diet alter seizure sensitivity and cell loss following fluid percussion injury? Epilepsy Res 92(1): 74-84.

9. Hu ZG, Wang HD, Jin W, Yin HX (2009) Ketogenic diet reduces cytochrome c release and cellular apoptosis following traumatic brain injury in juvenile rats. Ann Clin Lab Sci 39(1): 76-83.

10. Hu ZG, Wang HD, Qiao L, Yan W, Tan QF, et al. (2009) The protective effect of the ketogenic diet on traumatic brain injury-induced cell death in juvenile rats. Brain Inj 23(5): 459-465.

11. White H, Venkatesh K, Venkatesh B (2017) Systematic review of the use of ketones in the management of acute and chronic neurologic disorders. J Neuro Neurosci 8(2): 188.
12. Branco AF, Ferreira A, Simões RF, Novais SM, Zehowski C, et al. (2016) Ketogenic diets: from cancer to mitochondrial diseases and beyond. Eur J Clin Invest 46(3): 285-298.

13. Robertson CS, Goodman JC, Narayan RK, Contant CF, Grossman RG (1991) The effect of glucose administration on carbohydrate metabolism after head injury. J Neurosurg 74(1): 43-50.

14. Ritter AM, Robertson CS, Goodman JC, Contant CF, Grossman RG (1996) Evaluation of a carbohydrate-free diet for patients with severe head injury. J Neurotrauma 13(8): 473-485.

15. Arya R, Peariso K, Lein MG, Harvey J, Harvey J, et al. (2018) Efficacy and safety of ketogenic diet for treatment of pediatric convulsive refractory status epilepticus. Epilepsy Res 144: 1-6.

16. Redmond C, Lipp J (2006) Traumatic brain injury in the pediatric population. Nutr Clin Practice 21(5): 450-461.

17. Bu JAC, Reeves JH, Patel JJ, Morris CR, Hurt RT (2017) Protein requirements of the critically ill pediatric patient. Nutr Clin Practice 32 (suppl 1): 128S-141S.

18. Kerklaan D, Augustus ME, Hulst JM, Rosmalen J, Verbuggen SCAT, et al. (2016) Validation of ventilator derived $\mathrm{VCO}_{2}$ measurements to determine energy expenditure in ventilated critically ill children. Clinl Nutr 36(2): 452-457.

19. Franklin GA, McClave SA, Hurt RT, Lowen CC, Stout AE, et al. (2011) Physician-delivered malnutrition: why do patients receive nothing by mouth or a clear liquid diet in a university hospital setting? JPEN J Parenter Enteral Nutr 35(3): 337-342.

20. Mehta NM, Bechard LJ, Dolan M, Ariagno K, Jiang H, et al. (2011) Energy imbalance and the risk of overfeeding in critically ill children. Pediatr Crit Care Med 12(4): 398-405.

21. Mtaweh H, Smith R, Kochanek PM, Wisniewski SR, Fabio A, et al. (2014) Energy expenditure in children after severe traumatic brain injury. Pediatr Crit Care Med 15(3): 242-249. 